\title{
Optimal Nozzle Structure for an Abrasive Gas Jet for Rock Breakage
}

\author{
Yong Liu $\mathbb{D}^{1,2,3}$ Juan Zhang $\mathbb{D}^{1,2}$ Tao Zhang, ${ }^{1,2}$ and Huidong Zhang ${ }^{1,2}$ \\ ${ }^{1}$ State Key Laboratory Cultivation Base for Gas Geology and Gas Control, Henan Polytechnic University, Jiaozuo, \\ 454000 Henan, China \\ ${ }^{2}$ School of Safety Science and Engineering, Henan Polytechnic University, Jiaozuo, 454000 Henan, China \\ ${ }^{3}$ Coal Production Safety Collaborative Innovation Center in Henan Province, Jiaozuo, 454000 Henan, China
}

Correspondence should be addressed to Yong Liu; yoonliu@126.com

Received 12 June 2018; Revised 11 August 2018; Accepted 10 September 2018; Published 30 October 2018

Guest Editor: Fangtian Wang

Copyright ( 2018 Yong Liu et al. This is an open access article distributed under the Creative Commons Attribution License, which permits unrestricted use, distribution, and reproduction in any medium, provided the original work is properly cited.

\begin{abstract}
Abrasive gas jet technologies are efficient and beneficial and are widely used to drill metal and glass substrates. When the inlet pressure is increased, gas jets could be powerful enough to break rock. They have potential uses in coal-bed methane exploration and drilling because of their one-of-a-kind nonliquid jet drilling, which avoids water invasion and borehole collapse. Improving the efficiency of rock breakage using abrasive gas jets is an essential precondition for future coal-bed methane exploration. The nozzle structure is vital to the flow field and erosion rate. Furthermore, optimizing the nozzle structure for improving the efficiency of rock breakage is essential. By combining aerodynamics and by fixing the condition of the nozzle in the drill bit, we design four types of preliminary nozzles. The erosion rates of the four nozzles are calculated by numerical simulation, enabling us to conclude that a nozzle at Mach 3 can induce maximum erosion when the pressure is $25 \mathrm{MPa}$. Higher pressures cannot improve erosion rates because the shield effect decreases the impact energy. Smaller pressures cannot accelerate erosion rates because of short expansion waves and low velocities of the gas jets. An optimal nozzle structure is promoted with extended expansion waves and less obvious shield effects. To further optimize the nozzle structure, erosion rates at various conditions are calculated using the single-variable method. The optimal nozzle structure is achieved by comparing the erosion rates of different nozzle structures. The experimental results on rock erosion are in good agreement with the numerical simulations. The optimal nozzle thus creates maximum erosion volume and depth.
\end{abstract}

\section{Introduction}

A high-pressure gas jet is efficient for drilling and cutting metal or glass. It has been widely used to drill hard and brittle materials for several decades [1-3]. To date, researchers have used the technology for rock or coal breakage in coal-bed methane exploration [4-6]. As a nonliquid invasive jet, the abrasive gas jet avoids borehole collapse, which is mainly induced by water invasion during assisted drilling with high-pressure water jets [7-9]. Like supercritical $\mathrm{CO}_{2}$, the abrasive gas jet has great potential for assisted drilling and perforation in coal-bed methane exploration [10]. The assumption is that high-pressure abrasive gas jet is powerful and effective enough to break rock and coal. There are many methods that improve the impact force of abrasive gas jets.
The most significant method is optimization of the nozzle structure.

For compressible fluid jets, the nozzle structure decides the outlet velocity and flow-field structure [11]. There are many nozzle types (e.g., straight nozzle, Laval nozzle, and convergent nozzle) available for rock breakage. Fortunately, many studies have provided essential guidance. Tan et al. proposed that the inclusion of a Laval nozzle would magnify the velocity and eliminate the instability of the airflow field. They also conjectured that the Laval nozzle was best equipped for high velocity and stable flow fields [12]. Li et al. found that the flow generated by the Laval nozzle had a higher exit velocity in the vicinity of the nozzle, compared to a straight nozzle. Thus, a Laval nozzle is more efficient than a straight one. The flow generated by a Laval nozzle is 
also less convergent, and the velocity gradient along the radial direction is more moderate than a straight nozzle [13], according to flow characteristics. The Laval nozzle is considered a better choice for rock and coal breakage. Alkhimov et al. studied the relationship between nozzle structure and final exit velocity of particles, finding an optimizing structure and substream length [14]. Huang et al. investigated nozzle configurations on rock erosion by comparing convergent and Laval nozzles. He concluded that the Laval nozzle enhanced rock erosion, depending on pressure and temperature conditions. Additionally, the jet from a nozzle with a smooth inner profile always had a greater erosion ability than a Laval with a broken line inner profile [15].

The reason why nozzle structure affects the outlet pressure is that it decides the expansion status of the gas jet. The expansion status depends on the ratio of static pressures between the outlet and the atmosphere, which is equal to the rate of the section between the nozzle outlet and inlet [16]. The expansion status is significant to the flow field, which is substantial to abrasive acceleration and abrasive velocity impacting the material [17]. Gregorio investigated the compressibility effect on a supersonic turbulent jet with a nozzle Mach exit of $\mathrm{Ma}=1.5$. The results showed that the overexpanded jet presented a larger spreading rate than other conditions. The overexpanded jet was characterized by a strong shock immediately downstream of the nozzle exit, inducing a speed deceleration to $\mathrm{Ma}=1.1$. The fully expanded state was described by a slight overpressure value with respect to the ambient conditions, presenting a train of weak expansion and oblique shock waves. The underexpanded jet showed extreme Mach fluctuations owing to the stronger train of expansions and shock waves [18]. The underexpanded jet presented the best status for converting high gas velocities. Moreover, the Mach disc was an obvious barrier to obtaining a flow-field and high gas velocity, necessary for rock and coal breakage. Because the expansion status relates to the ratio of inlet and outlet pressures, the inlet pressure should be seriously investigated. Tan et al.'s research showed that the maximum value of gas jets increases with increasing inlet pressure. Thus, it oscillates, accompanied by the formation of compression waves in the supersonic region when the inlet pressure is larger than 15 psi. The simulation demonstrates that a Laval nozzle influences the airflow field by increasing the maximum value of the gas jet velocity and by eliminating the compression waves at specific expected values of the pressure inlet [12].

Whereas earlier investigations clarified the relation between nozzle structure and gas jets, the types of nozzle structures that best apply to accelerate abrasives have been rarely studied. The motion of abrasives in gas jets is so complicated that there is no consensual theory on an abrasive acceleration or abrasive erosion mechanisms. Such mechanisms would be significantly affected by gas pressure, abrasive concentration, abrasive size, abrasive density, etc. [19-25]. Ultimately, the only thing that matters is that this property increases the erosion rate of the abrasive gas jet. Thus, we are inspired to estimate the nozzle structure based on erosion rate.

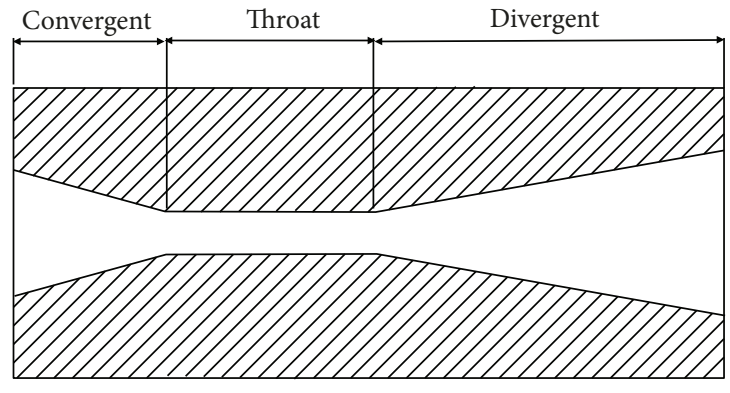

Figure 1: Structure of the Laval nozzle with a throat section.

To optimize the nozzle structure of an abrasive gas jet for rock and coal breakage, we designed a preliminary structure by combining aerodynamics and installing a drilling engineered nozzle. Moreover, the effects of various convergent angles, draw ratio of the throat, divergent angles, etc. on the erosion rate were obtained via numerical simulation, thus providing estimates for the optimal nozzle structures. Moreover, the results of numerical simulation are verified by erosion experiments. Finally, the optimal nozzle structure for rock and coal breakage induced with abrasive gas jets is proposed.

\section{Preliminary Nozzle Structure Design}

A Laval nozzle is a convergent-divergent nozzle, invented by Gustav Patrik de Laval in 1888 for steam engine applications to produce a supersonic flow in the divergent section, directly following the choked and sonic flow conditions at the narrowest point of the nozzle. Because his paper focused on the erosion rate of the abrasive gas jet, the abrasive velocity was the most relevant to rock breakage. The abrasive velocity largely depended on gas velocity and its gain. The gas velocity reached sonic proportions at the narrowest point, where it transitioned from the convergent section to the divergent section. Lengthening the narrowest section (i.e., throat section) prolonged the sonic and abrasive acceleration times, promoting the higher initial abrasive velocities at the entrance of divergent section and the higher impact velocities on the rock and coal. Thus, the Laval nozzle with a throat section was used to erode the rock, as shown in Figure 1. Because the abrasive velocity gained mainly from gas, the gas state and velocity of the nozzle should be cleared first.

Assuming the flow state is adiabatic and frictionless, the differential equations of a 1-dimensional steady flow in the nozzle are as follows.

The continuity equation is

$$
\frac{d V}{V}=-\frac{d A}{A}-\frac{d \rho}{\rho}
$$

where $V$ is volume, $A$ is a sectional area, and $\rho$ is density.

Momentum is

$$
V d V=-\frac{d \rho}{\rho} .
$$


Energy is

$$
\frac{d T}{T}+\frac{V d V}{c_{p} T}=0
$$

where $T$ is temperature and $c_{p}$ is constant-pressure specific heat.

State equation is

$$
\frac{d \rho}{\rho}=\frac{d p}{p}-\frac{d T}{T} .
$$

Momentum equation can be rewritten as

$$
\frac{V^{2} d V}{V}=-\frac{d p}{d \rho} \cdot \frac{d \rho}{\rho}=-a^{2} \frac{d \rho}{\rho},
$$

where $a$ is the local speed of sound.

By putting (1) and (5) together, we get

$$
\frac{d V}{V}=-\frac{1}{1-M^{2}} \frac{d A}{A}
$$

where $M$ is the Mach number.

Momentum can also be rewritten as

$$
\frac{V^{2} d V}{V}=-\frac{d p}{k p} a^{2}
$$

By putting (6) and (7) together, we get

$$
\frac{d p}{p}=\frac{k M^{2}}{1-M^{2}} \frac{d A}{A}
$$

Plugging (8) into (1), we get

$$
\frac{d \rho}{\rho}=\frac{k M^{2}}{1-M^{2}} \frac{d A}{A} .
$$

The second terms of the energy equation can be rewritten as $\left(V^{2} d V / V\right) \cdot\left((k-1) / a^{2}\right)$ and be plugged into (6), such that

$$
\frac{d T}{T}=\frac{(k-1) M^{2}}{1-M^{2}} \frac{d A}{A} .
$$

It is clear that the thermodynamic parameters (e.g., $p$, $T$, and $\rho$ ) of the gas jet depend on the changes of nozzle section. Thus, these parameters can be calculated by nozzle section area based on (8), (9), and (10). To optimize the nozzle structure, the way the ratio of the nozzle section area affects the thermodynamics parameter should be figured out first. The continuity equation can be rewritten as

$$
\rho V A=\rho^{*} V^{*} A^{*}
$$

where $\rho^{*}$ is the critical density, $V^{*}$ is the critical volume, and $A^{*}$ is the critical sectional area.

Owing to $V^{*}$ being equal to $a^{*}$ and the critical velocity of sound, (11) can be rewritten as

$$
\frac{A}{A^{*}}=\frac{\rho^{*}}{\rho_{0}} \cdot \frac{\rho_{0}}{\rho} \cdot \frac{a^{*}}{a_{0}} \cdot \frac{a_{0}}{a} \cdot \frac{a}{V} .
$$

The first four items of the right side of (12) can be replaced with a constant entropy equation related to $M$. The fifth item is equal to $M^{-1}$. Thus, (12) can be rewritten as

$$
\frac{A}{A^{*}}=\frac{1}{M}\left(\frac{2}{k+1}\right)^{(k+1) /(2(k-1))}\left(1+\frac{k-1}{2} M^{2}\right)^{(k+1) /(2(k))} \text {. }
$$

According to (13), the relationship between the Mach number of the nozzle exit and the ratio of the sectional area can be obtained. The sectional area of the nozzle exit can be confirmed by setting the Mach number and the sectional area of the nozzle entrance in advance. For rock and coal erosion, the larger the Mach number at the nozzle exit, the better the abrasive gas jet erodes rock and coal, and the larger the sectional area at the nozzle exit. However, it is impossible to enlarge the sectional area infinitely, because the fixing position is limited by the coal-bed methane well. The permitted maximum length of the nozzle is $40 \mathrm{~mm}$, and the maximum sectional area of nozzle entrance and outlet is $4 \mathrm{~mm}$ and $10 \mathrm{~mm}$, respectively, based on the size of the drill bit. By combining the thermodynamic equations and the size of the fixed position of the drill bit, four initial nozzle structures can be designed. Their outlet velocities are Mach numbers 2, 3, 4, and 5, as shown in Figure 2.

\section{Further Optimizing the Laval Nozzle}

The four Laval nozzles, discussed in Section 2, differ with outlet velocity. Moreover, the nozzle having a Mach 5 outlet velocity is efficient for energy transformation. However, it cannot tell when it is the best to accelerate to abrasive mode to erode the rock and coal, because abrasive acceleration relates not only to gas velocity but also to gas density, viscosity, temperature, pressure gradient, etc. [26-29]. Furthermore, the inlet pressure is critical to abrasive acceleration and velocity, because it determines the expansion state of the gas jet. Moreover, the convergent angle, divergent angle, and draw ratio of the nozzle throat section dramatically affect the expansion state. Thus, the Laval nozzle should be specially designed. We use ANSYS-FLUENT as an efficient analysis of the flow-field of the gas jet. Its discrete phase model (DPM) can precisely resolve the abrasive motion. It provides an erosion model to calculate the erosion rate of the target material. 


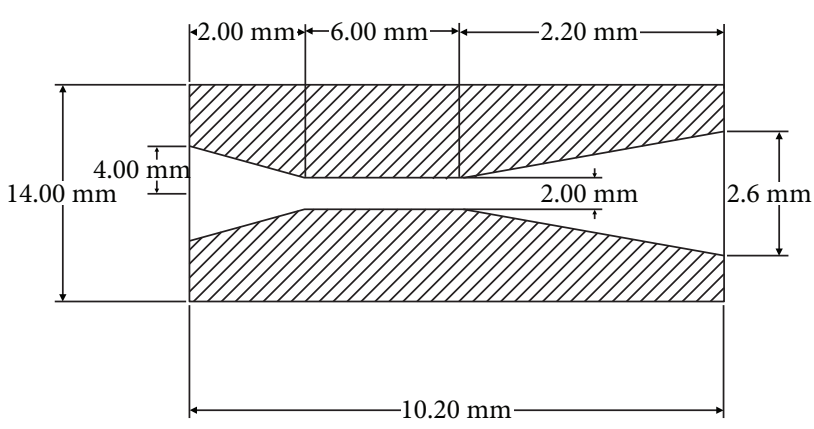

(a) Mach 2

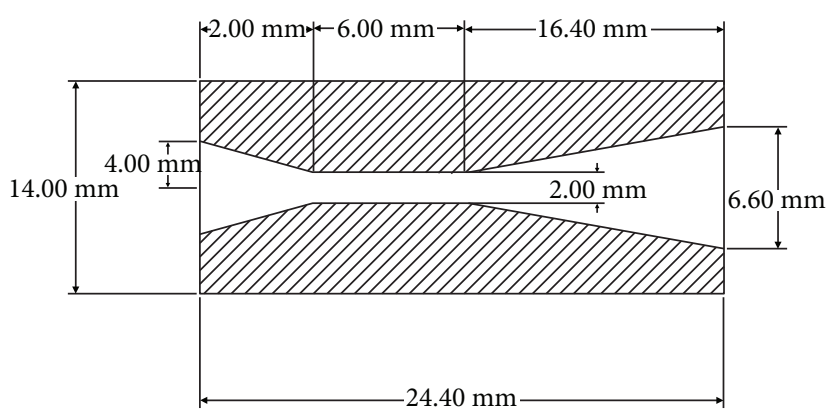

(c) Mach 4

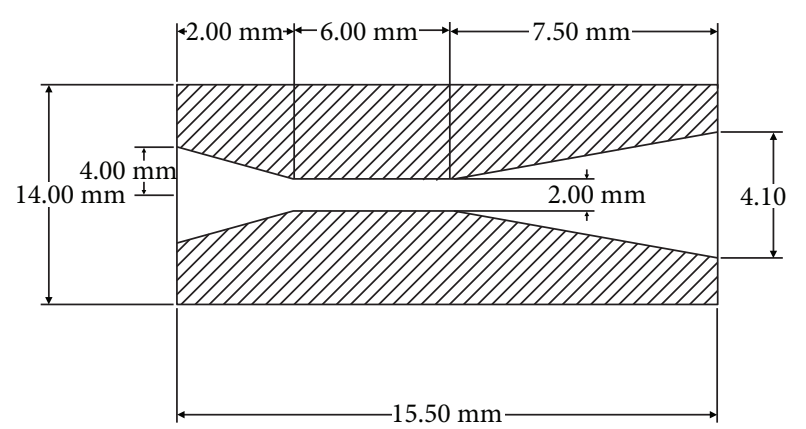

(b) Mach 3

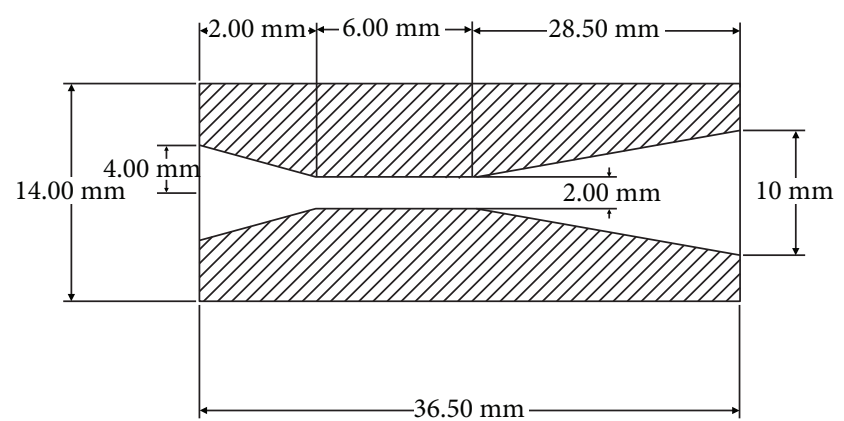

(d) Mach 5

FIGURe 2: Preliminary Laval nozzle structure.

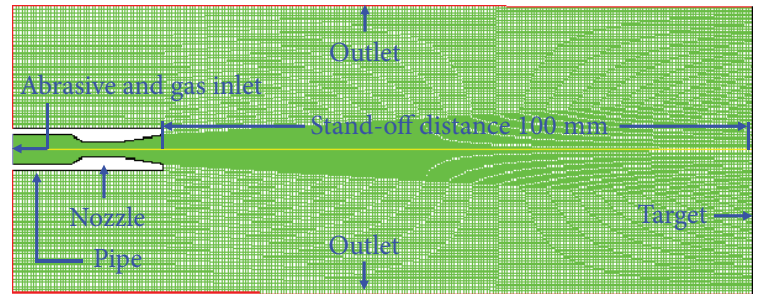

Figure 3: Geometrical model of numerical simulation.

Thus, this section focuses on the effects of various initial FLUENT conditions and structures of the erosion rate of rock.

3.1. Numerical Simulation Model. According to erosion parameters (e.g., nozzle parameter), when the stand-off distance is $100 \mathrm{~mm}$, the numerical simulation geometry model is designed as shown in Figure 3. A structured grid is used for mesh division, and the mesh number is 17,240 , based on the mesh sensitivity analysis. The inlet boundary is the pressure inlet; the outlet boundary is the pressure outlet; and the wall surface is a nonslip wall. Whereas the inlet temperatures are all $300 \mathrm{~K}$ and the outlet pressures are all $0.1 \mathrm{MPa}$, the garnet abrasive is $3500 \mathrm{~kg} / \mathrm{m}^{3}$, and the diameter is $180 \mu \mathrm{m}$. The gas and solid phases are calculated based on the continuous and discrete phase models. Following the convergence and stability of the gas phase, the DPM model calculates abrasives' parameters (e.g., velocity and spatial locations).

For the gas phase, the RNG $k-\varepsilon$ turbulence model can simulate a high Reynolds number flow of jets. The gas is assumed to be an ideal gas. The governing equations for the RNG $k-\varepsilon$ turbulence model are described in [30].

$$
\begin{aligned}
\frac{\partial(\rho k)}{\partial t}+\frac{\partial\left(\rho k u_{i}\right)}{\partial x_{i}}= & \frac{\partial}{\partial x_{i}}\left[\alpha_{k} \mu_{e f f} \frac{\partial k}{\partial x_{j}}\right]+G_{k}+G_{b}-\rho \varepsilon-Y_{M} \\
\frac{\partial(\rho \varepsilon)}{\partial t}+\frac{\partial\left(\rho \varepsilon u_{i}\right)}{\partial x_{i}}= & \frac{\partial}{\partial x_{j}}\left[\alpha_{\varepsilon} \mu_{e f f} \frac{\partial \varepsilon}{\partial x_{j}}\right] \\
& +C_{1 \varepsilon} \frac{\varepsilon}{k}\left(G_{k}+C_{3 \varepsilon} G_{b}\right)-C_{2 \varepsilon} \rho \frac{\varepsilon^{2}}{k}
\end{aligned}
$$

where

$$
\begin{aligned}
\mu_{e f f} & =\mu+\mu_{t}, \\
\mu_{t} & =\rho C_{u} \frac{k^{2}}{\varepsilon}, \\
G_{b} & =\varphi g_{i} \frac{\mu_{t}}{\operatorname{Pr}_{t}} \frac{\partial T}{\partial x_{i}}, \\
G_{k} & =\mu_{t}\left(\frac{\partial \mu_{i}}{\partial x_{j}}+\frac{\partial u_{j}}{\partial x_{i}}\right) \frac{\partial \mu_{i}}{\partial x_{j}}, \\
Y_{M} & =2 \rho \varepsilon \frac{k}{a^{2}} .
\end{aligned}
$$

$\rho$ is density; $k$ is turbulent kinetic energy; $\varepsilon$ is dissipation rate of $k ; t$ is time; $x_{i}$ are the Cartesian coordinates; $u_{i}$ and $u_{j}$ are velocity components along $i$ and $j ; \mu$ is gas viscosity; $\mu_{t}$ is 
eddy viscosity; $G_{k}$ is the generation term of the turbulent kinetic energy, $k$, resulting from the mean velocity gradient; $G_{b}$ is the generation term of the turbulent kinetic energy from buoyancy; $Y_{M}$ is the effect of compressible turbulent pulsatile expansion on the total dissipation rate; and $\alpha_{k}$ and $\alpha_{\varepsilon}$ are the reciprocals of the effective Prandtl numbers for turbulent kinetic energy and dissipation rates. $P r_{t}$ is the turbulence Prandtl number; $C_{1 \varepsilon}, C_{2 \varepsilon}$, and $C_{3 \varepsilon}$ are empirical constants; $g_{i}$ is the component of gravitational acceleration in the $i$ direction, $\varphi$ is the thermal expansion coefficient, and $a$ is the acoustic velocity.

The gas phase continuity equation is

$$
\frac{\partial\left(\varepsilon_{f} \rho_{f}\right)}{\partial t}+\left(\nabla \cdot \varepsilon_{f} \rho_{f} \vec{u}\right)=0
$$

The gas phase Navier-Stokes equation is

$$
\begin{aligned}
\frac{\partial\left(\varepsilon_{f} \rho_{f} \vec{u}\right)}{\partial t}+\left(\nabla \cdot \varepsilon_{f} \rho_{f} \vec{u} \vec{u}\right)= & -\varepsilon_{f} \cdot \nabla \mathrm{P}-\vec{F}_{f p} \\
& -\left(\nabla \cdot \varepsilon_{f} \rho_{f} \tau_{f}\right)+\left(\varepsilon_{f} \rho_{f} \vec{g}\right)
\end{aligned}
$$

where $\varepsilon_{f}$ is the gas volume fraction; $\rho_{f}$ is the gas density, $\mathrm{kg} / \mathrm{m}^{3} ; t$ is the time, $\mathrm{s} ; \vec{u}$ is gas velocity vector, $\mathrm{m} / \mathrm{s} ; P$ is pressure, $\mathrm{kPa} ; \vec{F}_{f p}$ is fluid particle interaction force, $\mathrm{N} ; \tau_{f}$ is gas phase stress tensor; and $\vec{g}$ is gravity acceleration vector, $\mathrm{m} / \mathrm{s}^{2}$.

The DPM of the particle phase is given as in $[26,31]$ :

$$
\frac{d u_{p}}{d t}=F_{D}\left(u_{f}-u_{p}\right)+\frac{g\left(\rho_{p}-\rho_{f}\right)}{\rho_{p}}+F_{x}
$$

where $F_{D}\left(u-u_{p}\right)$ is the drag force per unit particle mass.

$$
\begin{aligned}
F_{D} & =\frac{18 \mu_{m}}{d_{p}^{2} \rho_{p}} C_{D} \frac{\operatorname{Re}_{p}}{24}, \\
\operatorname{Re}_{p} & =\frac{\rho_{f} d_{p}\left|u_{p}-u_{f}\right|}{u_{f}},
\end{aligned}
$$

where $F_{x}$ is an additional acceleration caused by the Saffman lift force. Pressure gradient $u_{p}$ is the particle velocity, $u_{f}$ is the velocity of the fluid, $g$ is gravity acceleration, $\rho_{p}$ is the density of the particle, $d_{p}$ is the diameter of the particle, $C_{D}$ is the drag coefficient, and $\mathrm{Re}_{p}$ is the relative Reynolds number.

FLUENT provides erosion models for analyzing the erosion rate of the target material. Among those, the McLaury erosion model is optimal for investigating rock erosion of abrasive gas jets, because the particle velocity, shape, diameter, etc. are considered $[32,33]$.

$$
E_{R}=A F_{s} v_{p}^{n} f(\theta)
$$

where $E_{R}$ is the target erosion; $A$ is the Brinell hardness of the material; $F_{s}$ is a particle shape coefficient; $n$ is constant; and $F_{\text {s }}=1.0$ for sharp (angular), 0.53 for semi-rounded, or 0.2 for sully rounded sand particles. Morsi and Alexander used two functional forms of angle dependence, with matching conditions applied at some intermediate angle, $\theta_{0}$. The dependence on impingement angle, $\theta$, is given in (21) [34].

$$
f(\theta)= \begin{cases}m_{1} \theta^{2}+m_{2} \theta & \text { for } \theta \leq \alpha \\ m_{3} \cos ^{2} \theta \sin (w \theta)+m_{4} \sin ^{2} \theta+z & \text { for } \theta>\alpha\end{cases}
$$

where $m_{1}, m_{2}, m_{3}, m_{4}, w, z$, and $\alpha$ are empirical constants.

3.2. Verifying of Outlet Velocity of the Laval Nozzle. Equation (13) shows that the Mach number of the nozzle exit only relates to the ratio of the sectional area between the inlet and outlet. The inlet pressure cannot affect the Mach number but can affect the ratio of static pressure between the outlet pressure and atmosphere. To verify the preliminary nozzle structure and numerical simulation model, the data of the Mach number of the jet axial is extracted and shown in Figure 4. The Mach number of the nozzle exit reflects the theoretical analysis. Thus, the preliminary nozzle structure and the numerical simulation model are available in this study.

3.3. Effect of Pressure on Erosion Rate. Inlet pressure can dramatically affect expansion state, deciding the flow-field structure and abrasive acceleration. When the nozzle structure does not change, every nozzle has its own best pressure to erode rock at the greatest extent possible. It is necessary, then, to find the best pressure of abrasive gas jets for rock breakage. If the inlet pressure is too small, the velocity of the abrasive cannot be accelerated high enough, leading to a lesser erosion rate. However, if the inlet pressure is too large, the velocity of abrasive can be accelerated extremely high, but it aggravates the wear of the nozzle and shortens its service time. To find the best inlet pressures of the four nozzles and nozzle structure, the erosion rate will be calculated when the inlet pressure is $10 \mathrm{MPa}, 15 \mathrm{MPa}, 20 \mathrm{MPa}, 25 \mathrm{MPa}, 30 \mathrm{MPa}$, and $50 \mathrm{MPa}$. The most used abrasive of oil and natural gas well drilling is garnet with a diameter of 80 mesh, reflecting the initial parameters of the solid phase of the numerical simulation. The stand-off distance of good drilling is typically $0-100 \mathrm{~mm}$. Moreover, the larger the stand-off distance, the smaller the impact force and velocity of abrasive when the stand-off distance is beyond optimal value. The optimal stand-off distance depends on the potential core of the abrasive gas jet. To rid the effect of optimal stand-off distances and potential cores, confusing the comparison of erosion rate at the different initial condition, the initial stand-off distance is $100 \mathrm{~mm}$ of the numerical simulation.

We extract the maximum erosion rate of every numerical simulation case, as shown in Table 1. Similar to the conclusion of Section 2, every nozzle has its own best pressure for creating the largest erosion rate. Therefore, the maximum erosion of the nozzle at Mach 2 is $7.92 \times 10^{-6} \mathrm{~kg} / \mathrm{m}^{2} \cdot \mathrm{s}$ when the pressure is $25 \mathrm{MPa}$. The biggest erosion rate of 


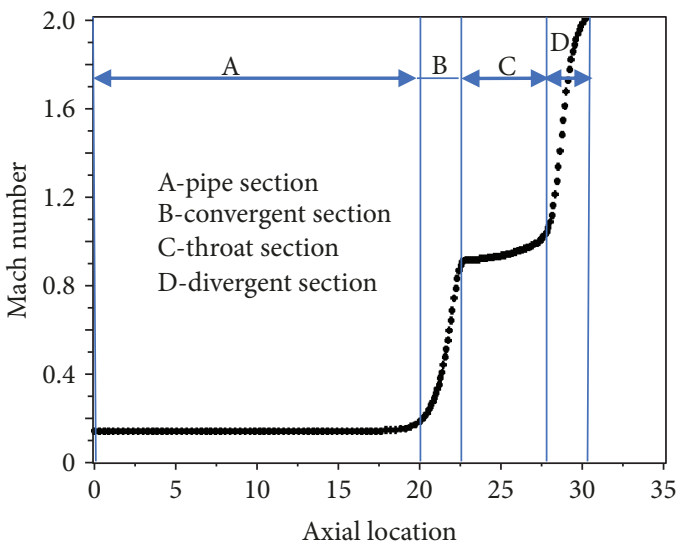

(a) Mach 2

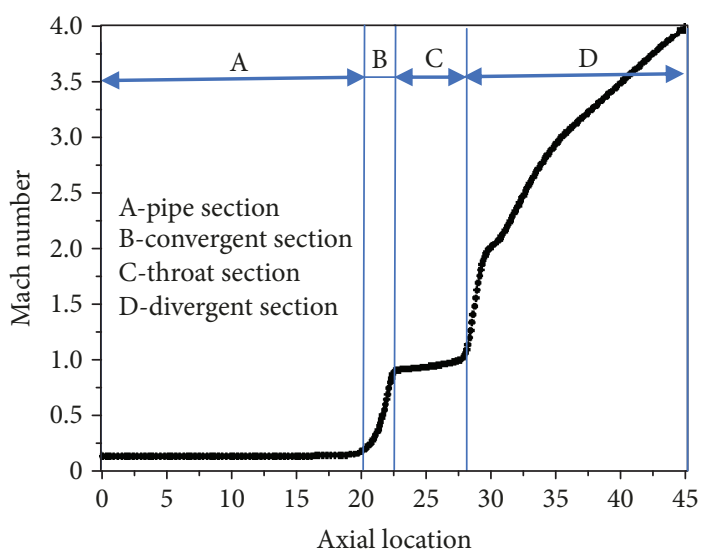

(c) Mach 4

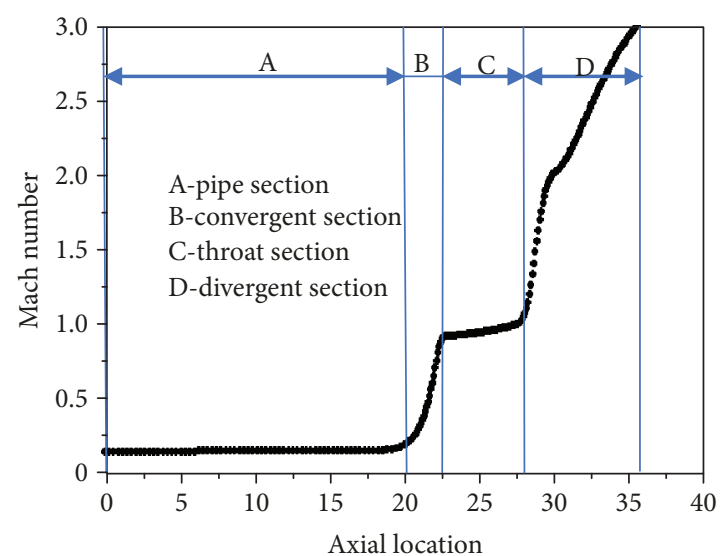

(b) Mach 3

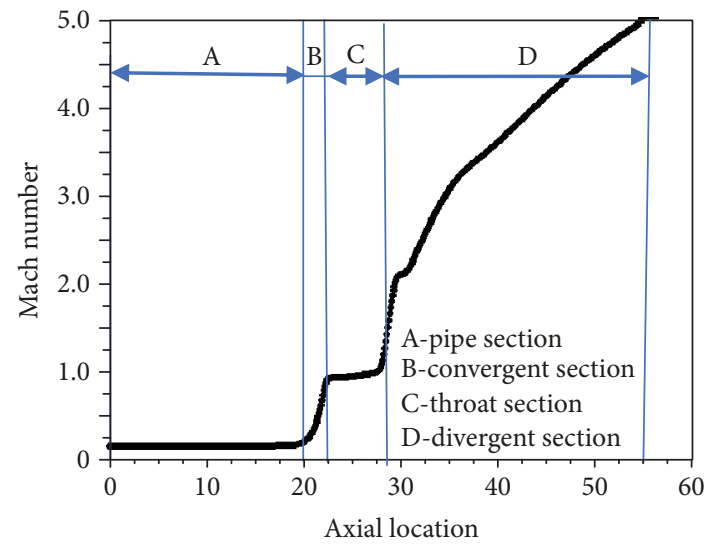

(d) Mach 5

Figure 4: Mach number of the gas jets at nozzle exits.

TABLE 1: Maximum erosion rate of different nozzles at various pressures.

\begin{tabular}{lcccccc}
\hline \multirow{2}{*}{ Nozzle } & \multicolumn{5}{c}{ Erosion rate $\left(\times 10^{-7} \mathrm{~kg} / \mathrm{m}^{2} \cdot \mathrm{s}\right)$} \\
& $10 \mathrm{MPa}$ & $15 \mathrm{MPa}$ & $20 \mathrm{MPa}$ & $25 \mathrm{MPa}$ & $30 \mathrm{MPa}$ & $50 \mathrm{MPa}$ \\
\hline Mach 2 & 10.9 & 12.5 & 19.3 & 79.2 & 10.7 & 4.56 \\
Mach 3 & 13.1 & 24.3 & 60.6 & 126 & 15.7 & 2.95 \\
Mach 4 & 15.1 & 13.4 & 17.2 & 13.5 & 16.3 & 7.17 \\
Mach 5 & 13.0 & 7.27 & 16.1 & 65.5 & 12.8 & 4.56 \\
\hline
\end{tabular}

the numerical simulation case is $1.26 \times 10^{-5} \mathrm{~kg} / \mathrm{m}^{2} \cdot \mathrm{s}$ when the pressure is $25 \mathrm{MPa}$, and the nozzle type is Mach 3 . Figure 5 shows the result of the nozzle at Mach 3 with various pressures, causing different erosion rates, owing to pressure changes.

Because the abrasive gas jet velocity depends on the gas jet flow field, we should clearly define how the pressure affects the gas jet flow field. When the gas exits the nozzle, the jet flow field depends on the ratio of static pressure between the gas jet and atmosphere. When the inlet pressure is $10 \mathrm{MPa}$, the outlet static pressure is $0.28 \mathrm{MPa}$. Thus, the gas does not completely expand. The gas expands continuously after flowing out of the nozzle, squeezing the boundary air.
This leads to the formation of an expansion wave, causing the gas jet to expand in the radial direction and increase the potential jet core. Moreover, the gas velocity in the axial direction further accelerates. Meanwhile, the static pressure of the gas jet gradually decreases with the expansion of the gas jet. The gas jet ceases to expand when static pressure is less than the atmosphere, and the gas jet velocity reaches the maximum. The expansion wave continually reflects the boundary of jet and overlays, leading to the formation of compression waves. The gas ceases to expand in a radial direction and begins to compress in the axial direction, shrinking the boundary of the potential core and decreasing the gas velocity. However, the density and static pressure of the gas jet increase with the formation and propagation of the compression wave. When the static pressure increases to $0.19 \mathrm{MPa}$, the gas jet has enough internal energy to expand. Then, the compression wave reflects the boundary and begins to expand again. By comparing the first expansion wave, the static pressure of the second expansion wave is smaller. The reflected angle of the expansion wave will be small, and the wavelength will be short. The expansion and compression waves propagate forward, alternatively in this fashion.

The larger the inlet pressure, the larger the outlet static pressure, leading to an increase of expansion waves and a 

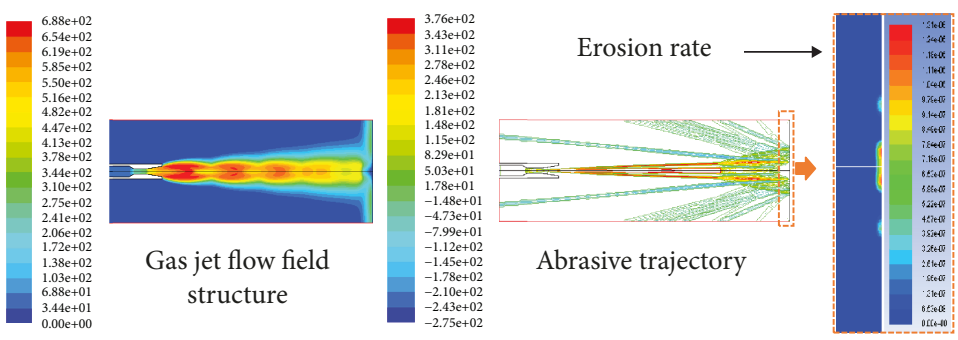

(a) $10 \mathrm{MPa}$
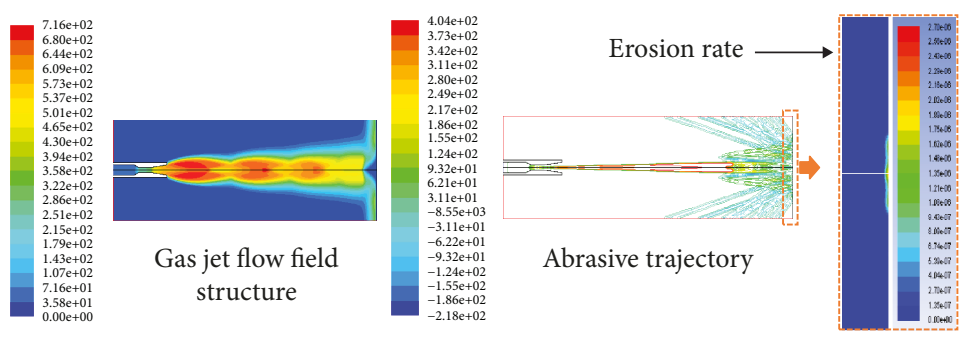

(b) $15 \mathrm{MPa}$
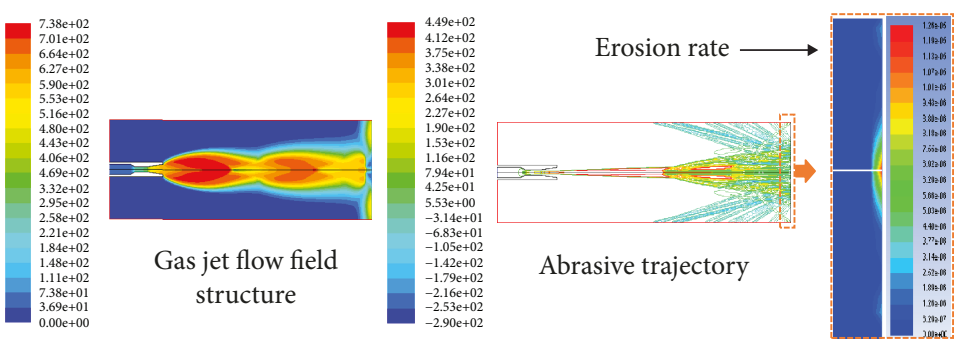

(c) $25 \mathrm{MPa}$
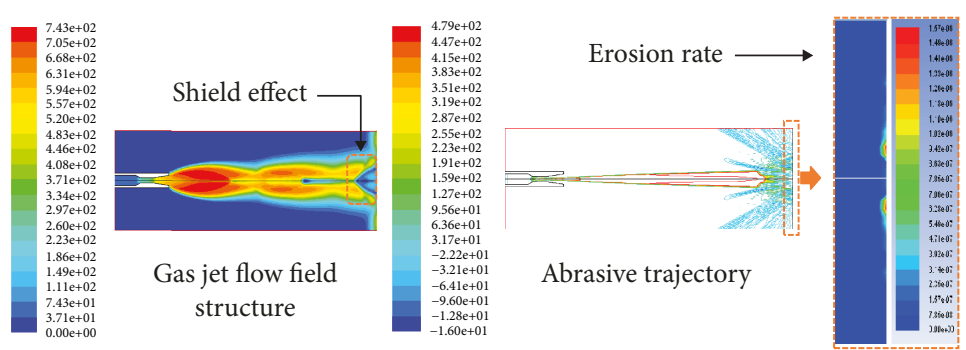

(d) $30 \mathrm{MPa}$
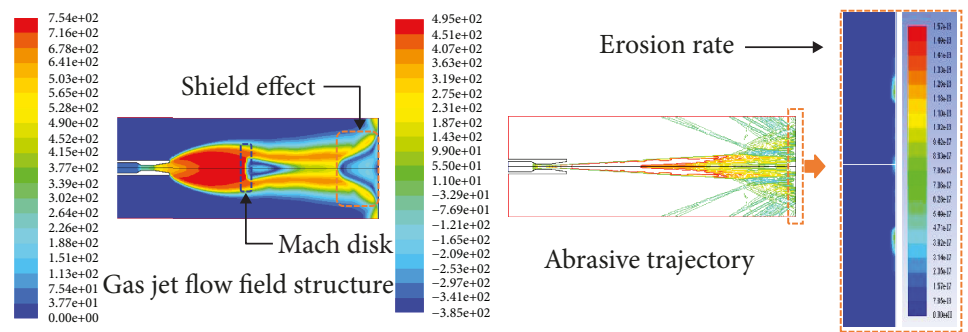

(e) $50 \mathrm{MPa}$

Figure 5: Flow field of gas jet and erosion rate at a variable pressure of nozzle Mach 3.

decrease of compression waves. An extended expansion wave creates a higher gas velocity, favorable and essential to abrasive acceleration. However, when the pressure is $30 \mathrm{MPa}$, the shield effect is evident and obstructive to abrasive erosion. The shield effect is much more apparent when pressure increases. Additionally, when the pressure reaches $50 \mathrm{MPa}$, there is a Mach disk next to the nozzle exit. It is wellknown that, when the ratio between static pressure and the atmosphere is large enough, the gas jet will overexpand, leading to a Mach disc. Whereas the gas velocity prior to the Mach disk is the largest, the gas velocity decreases significantly after the Mach disk is created. Then, the shield effect 

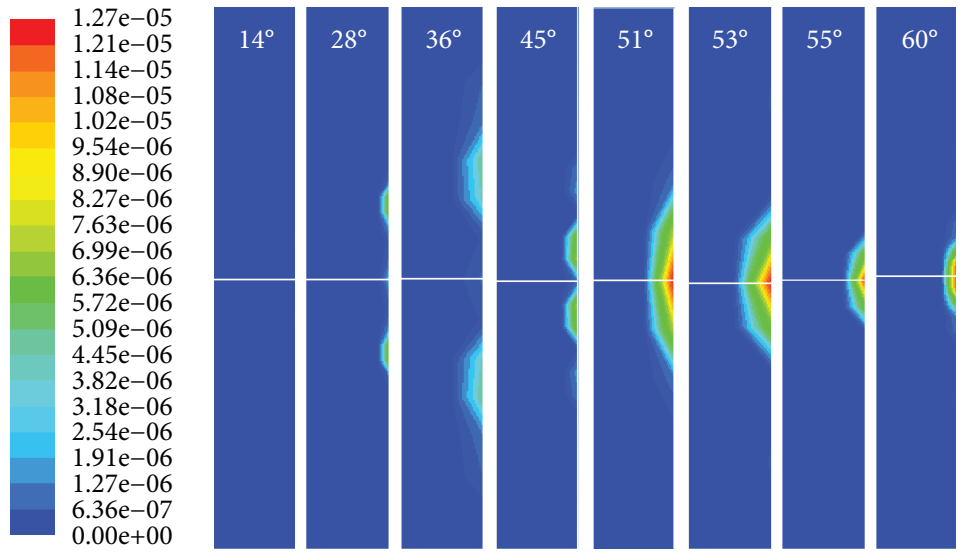

FIgURE 6: Erosion rate of rock at different divergent Laval nozzle angles.

TABLE 2: Erosion rate of rock at different divergent angles.

\begin{tabular}{|c|c|c|c|c|c|c|c|c|}
\hline Divergent angle & $14^{\circ}$ & $28^{\circ}$ & $36^{\circ}$ & $45^{\circ}$ & $51^{\circ}$ & $53^{\circ}$ & $55^{\circ}$ & $60^{\circ}$ \\
\hline Erosion rate $\left(\times 10^{-7} \mathrm{~kg} / \mathrm{m}^{2} \cdot \mathrm{s}\right)$ & 2.76 & 11.2 & 17.6 & 18.4 & 102 & 127 & 123 & 48.0 \\
\hline
\end{tabular}

is the most obvious, causing the erosion rate to reduce dramatically. Compared to other flow fields, when inlet pressure is $25 \mathrm{MPa}$, the flow field has the most extended expansion wave and the most subtle shield effect. The most extended expansion wave causes the abrasive to accelerate to the highest velocity. The most subtle shield effect causes the impact energy of abrasive to transfer most efficiently into the breakage energy of rock. These are the two primary causes giving sufficient explanation to the best erosion rate of $25 \mathrm{MPa}$.

\section{Refining Nozzle Structure}

Abrasive acceleration depends not only on the gas flow field of a free jet but also on the flow field of the nozzle. The best flow field of a free jet should feature high velocity and an unobvious shield effect, entirely depending on the ratio of expansion ratio and inlet pressure. Refining internal nozzle structures (e.g., convergent angle, divergent angle, contraction ratio, and draw ratio) is merely related to the flow field of the nozzle. Like Section 3, we do not focus on how detailed the nozzle structure affects the flow field. We instead judge it from the erosion rate.

4.1. Effect of Convergent Angle on Erosion Rate. The convergent angle decides the range of convergent section when the diameters of entrance and throat are being constant. While gas flows through the converging section, it will be first compressed and then released reaching a speed of sound. The high-speed gas jet then acts on abrasive hence abrasive acceleration. However, in order to achieve an excellent abrasive acceleration, convergent angle needs to be optimized. Specifically, a too large convergent angle results in a shorter convergent section with a nonuniform and unsteady gas jet, weakening the abrasion. Yet a too small convergent angle not only negatively affects abrasive acceleration but also brings difficulties in nozzle manufacturing. According to
TABLE 3: Erosion rates of rock at different contraction ratios.

\begin{tabular}{lcccccc}
\hline Contraction ratio & 1.5 & 2 & 2.5 & 3 & 3.5 & 4 \\
\hline Erosion rate $\left(\times 10^{-7} \mathrm{~kg} / \mathrm{m}^{2} \cdot \mathrm{s}\right)$ & 10.5 & 127 & 34.8 & 31.1 & 21.2 & 20.8 \\
\hline
\end{tabular}

aerodynamics experience, the convergent angle is suggested to range between $14^{\circ}$ and $60^{\circ}$. To further identify how the convergent angle affects the erosion rate, the erosion processes on rock are simulated with eight divergent angles in the following ranges: $14^{\circ}, 28^{\circ}, 36^{\circ}, 45^{\circ}, 51^{\circ}, 53^{\circ}, 55^{\circ}$, and $60^{\circ}$. The other influential parameters are fixed in the simulation. The results are presented in Figure 6 and Table 2. It is shown that divergent angle has a dramatical influence over the erosion rate. With an increasingly divergent angle, the erosion rate increases and then decreases. The maximum erosion rate is $1.27 \times 10^{-5} \mathrm{~kg} / \mathrm{m}^{2} \cdot \mathrm{s}$ when the divergent angle is $53^{\circ}$. When the convergent angle is less than $45^{\circ}$, the erosion rate of the target center is extremely small. The smaller the convergent angle is, the lower the erosion rate will be. By leveraging Figure 5, the smaller convergent angle leads to a more obvious shield effect, which is disadvantaged by the erosion rate. Higher convergent angles cause the gas jets to be difficult to accelerate and to become unstable in the flow field, leading to a decreased erosion rate.

4.2. Effect of Contraction Ratio on Erosion Rate. Contraction ratio refers to the ratio of the nozzle inlet radius to the throat radius. When the contraction ratio is less than 3 , the flow field of a gas jet of will be continuous and unseparated. The contraction ratio is designed to be within $1.5,2,2.5,3$, 3.5 , and 4 , whereas other structure parameters remain unchanged, except where at convergent of $53^{\circ}$. The erosion rate of rock at different contraction rates of Laval nozzle was calculated using the same numerical simulation method. The results are shown in Table 3 and Figure 7. Similar to Figure 6, when the contraction ratio equals 2, 


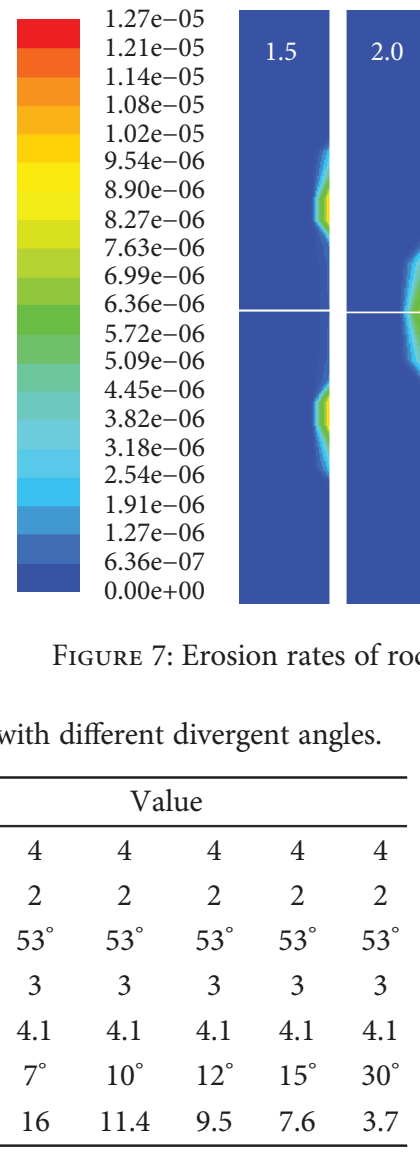

TABLE 5: Erosion rate of rock at different divergent angles.

\begin{tabular}{lcccccc}
\hline Divergent angle & $5^{\circ}$ & $7^{\circ}$ & $10^{\circ}$ & $12^{\circ}$ & $15^{\circ}$ & $30^{\circ}$ \\
\hline Erosion rate $\left(\times 10^{-7} \mathrm{~kg} / \mathrm{m}^{2} \cdot \mathrm{s}\right)$ & 120 & 127 & 153 & 127 & 66.1 & 18.2 \\
\hline
\end{tabular}

the shield effect is the most unobvious and is the primary cause of the maximum erosion rate. When the contraction ratio is less than 2.0 or too large, the shield effect decreases the impact energy of incident gas jets, making the wall jet too distant from the target center and inducing a decrease of erosion rate. A high erosion rate will cause a deeper erosion pit of rock, and a low erosion rate will cause the erosion pit of rock to be broader.

4.3. Effects of Divergent Angles on Erosion Rate. The divergent angle is a primary factor influencing expansion state and speed of a gas jet. Thus, it is critical to abrasive acceleration and rock erosion. When the divergent angle is between $5^{\circ}$ and $30^{\circ}$, the flow field of the gas jet improves. Based on the effect of convergent angle and contraction ratio on erosion rate, the structure of the Laval nozzle is refined further by adjusting the divergent angle among $5^{\circ}, 7^{\circ}, 10^{\circ}, 12^{\circ}, 15^{\circ}$, and $30^{\circ}$. The parameters of the Laval nozzle are listed in Table 4. The results of the numerical simulation are shown in Table 5 and Figure 8. The best erosion rate is $1.53 \times 10^{-7} \mathrm{~kg} / \mathrm{m}^{2} \cdot \mathrm{s}$. When the divergent angle is $10^{\circ}$, the erosion rate reaches maximum. The shield effect is subtle when the divergent angle resets between $5^{\circ}$ and $15^{\circ}$. If the divergent

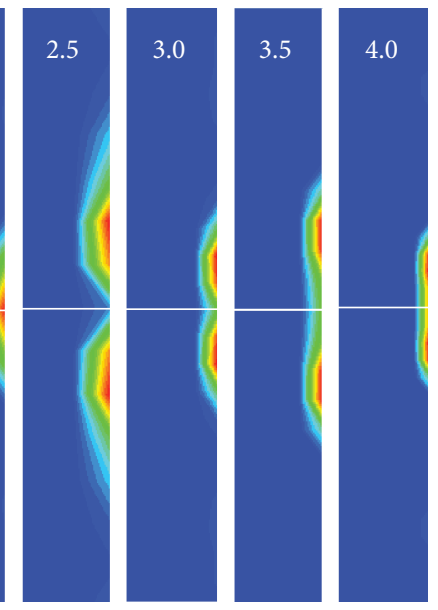

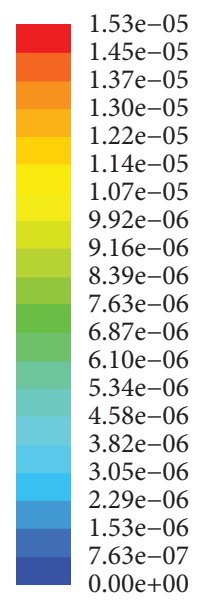
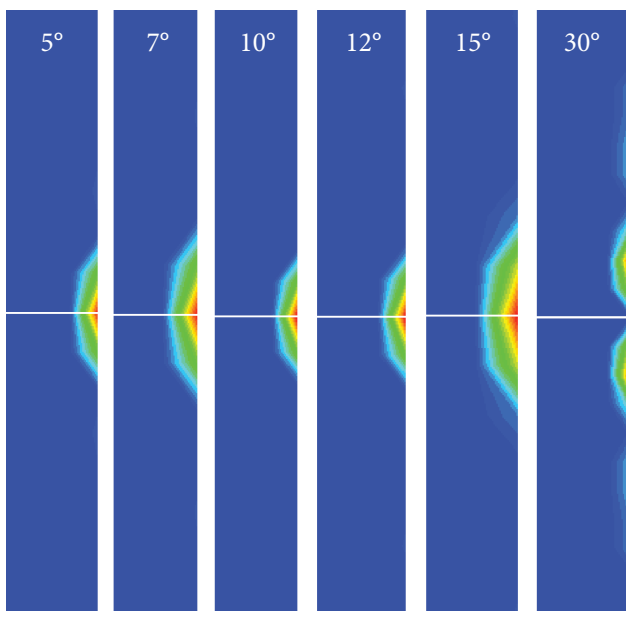

FIgURE 8: Erosion rate of rock at different divergent angles.

TABLE 6: Erosion rates of rock at different throat aspect ratios.

\begin{tabular}{lcccccc}
\hline Aspect ratio & 0 & 2 & 3 & 4 & 5 & 7 \\
\hline Erosion rate $\left(\times 10^{-7} \mathrm{~kg} / \mathrm{m}^{2} \cdot \mathrm{s}\right)$ & 9.64 & 127 & 153 & 71.2 & 34.4 & 26.1 \\
\hline
\end{tabular}

angle is too large (e.g., $30^{\circ}$ ), the shield effect is apparent and disadvantageous to rock erosion.

4.4. Effect of the Aspect Ratio of the Throat on Erosion Rate. The aspect ratio of the Laval nozzle refers to the ratio between throat length and diameter. For the gas phase, the velocity reaches the speed of sound and remains unchanged at the throat section. The length of the throat is not related to gas velocity. For solid phase, the length of the throat is significant to abrasive acceleration, because it determines the acceleration time of the abrasive. Thus, the erosion rate can improve when the aspect ratio of the throat is adjusted. To investigate the effect of the aspect ratio on erosion rate, we calculate the rate of rock erosion when the aspect ratio is 0 , $2,3,4,5$, and 7 . Meanwhile, the convergent angle is $53^{\circ}$, the contraction ratio is 2 , and the divergent angle is $10^{\circ}$. Results are shown in Table 6 and Figure 9. With the increasing aspect 


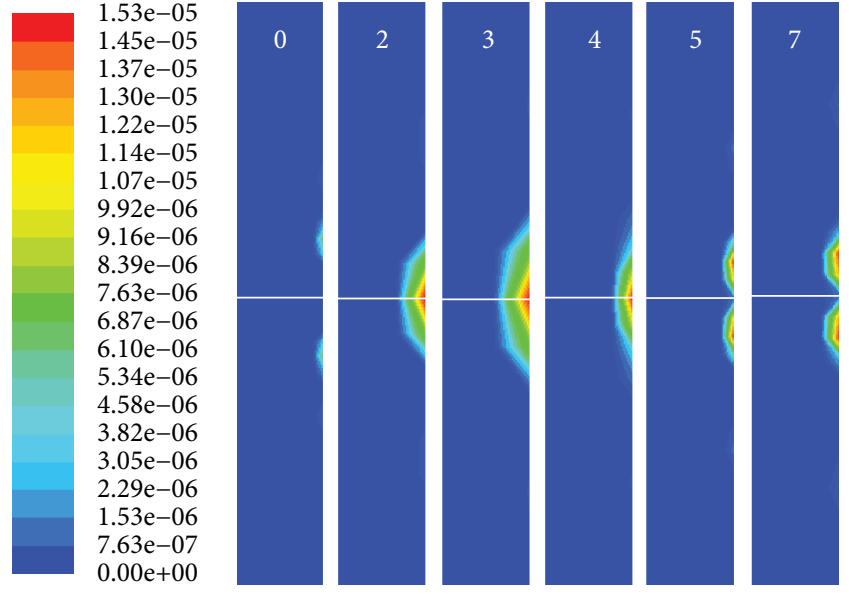

FIGURE 9: Erosion rate of rock at different throat aspect ratios.

ratio of the nozzle throat, the erosion rate increases and then decreases. When the aspect ratio is 0 , the length of the throat is 0 , and the erosion rate is minimized. The existence of a throat is vital to abrasive acceleration and erosion rate. The erosion rate reaches its maximum, $153 \times 10^{-7} \mathrm{~kg} / \mathrm{m}^{2} \cdot \mathrm{s}$, when the aspect ratio is 3 and the length is $6 \mathrm{~mm}$.

4.5. Optimal Nozzle Structure. From Section 3, we see that nozzle Mach 3 creates a comparatively maximum erosion rate. Nozzle structure is further refined by analyzing the effects of different convergent angles, contraction ratios, divergent angles, and aspect ratios on erosion rate. The single variable method is used to optimize the structural parameters and to get the optimal nozzle for rock breakage. The optimal nozzle structure parameters are at a convergent angle of $53^{\circ}$, a contraction ratio of 2 , a divergent angle of $10^{\circ}$, and an aspect ratio of 3 .

\section{The Rock Erosion Experiment}

To verify whether the nozzle structure is optimal, a rock erosion experiment was induced by comparing the erosion rate of relatively good nozzles, designed based on the optimal nozzle, as shown in Figure 10. Figure 10(a) shows the optimal nozzle. Based on the effect of the convergent angle on the erosion rate, the second best convergent angle is $60^{\circ}$. We change the convergent angle to $60^{\circ}$ and keep the other nozzle parameters unchanged, marked as nozzle b in Figure 10(b). Using the same method, we can associate nozzle $c$ with the transition of a divergent angle $\left(10^{\circ}\right)$ to divergent angle $\left(7^{\circ}\right)$, as shown in Figure 10(c). We can also obtain nozzle d associated with the transition of aspect ratio 3 to aspect ratio 5, as shown in Figure 10(d). Like the numerical simulation, the abrasive is garnet with mesh 80 , the inlet pressure is $25 \mathrm{MPa}$, the standoff distance is $100 \mathrm{~mm}$, and the erosion time is $10 \mathrm{~s}$.

5.1. Experimental System. The high-pressure abrasive gas jet erosion experimental system is used for the experiment, which consists of high-pressure air compressor, highpressure gas cylinder, digital pressure gauge, pressure control valve, abrasive tank, gate valve, and operation box. The high- pressure air compressor has a maximum pressure of $40 \mathrm{MPa}$ and a maximum air intake of $2 \mathrm{~m}^{3} / \mathrm{min}$, while the highpressure gas cylinder exhibits a maximum allowable pressure of $40 \mathrm{MPa}$. The system devices are connected as shown in Figures 11 and 12. The nozzle used is a Laval nozzle, whose structural parameters are the same as the nozzle used in the numerical simulation. Before the experiment, high-pressure gas is stored in the high-pressure gas cylinder, and the outlet pressure is adjusted with the pressure-regulating valve. The inlet pressure ranges between 0 and $40 \mathrm{MPa}$, whereas the outlet pressure ranges between 0 and $25 \mathrm{MPa}$. With an adjustable outlet pressure accuracy of $0.1 \mathrm{MPa}$, the pressure regulating valve can accurately control the jet pressure, thereby ensuring a constant jet pressure during the experiment to meet the experimental requirements. To precisely control the mass flow rate of abrasives, a high-pressure gate valve is installed below the abrasive tank. The gate is suitable for controlling the flow of solid particles under high-pressure conditions. Before the experiment, the gate valve scales corresponding to the mass flow of different abrasives are determined by calibration.

Limestone is used for erosion. To ensure that the mechanical and physical properties of the eroded limestone are identical, $\phi 50 \times 100$ rock samples are prepared by coring on the same rock mass. Two rock samples are selected and tested for mechanical properties using MTS, and the results are presented in Table 7 . Before performing the erosion experiment, the gas pressure in the gas tank is increased to over $35 \mathrm{MPa}$, the abrasive tank is filled with the corresponding abrasive, and the gate valve position is adjusted to ensure that the mass flow meets the requirements of experimental conditions. To improve the accuracy of the experimental result, we did a parallel experiment for every nozzle. We used every nozzle to erode three rock samples at the same experimental condition. The detailed experiment procedure is shown in Table 8.

5.2. Experiment Result. Erosion volume and erosion depth were the two primary parameters that reflected the erosion effect of the abrasive gas jet equal to the erosion rate. The results of erosion volume are shown in Table 9. Nozzle a creates the maximum erosion rate of $14.89 \mathrm{~mL}$, which is in good agreement with the numerical simulation. Nozzle $c$ creates minimum erosion rate of $9.38 \mathrm{~mL}$, where the divergent angle most dramatically affects the erosion rate. We obtain the same conclusion with the experimental results of erosion depth. Nozzle a makes a maximum erosion depth of $47.29 \mathrm{~mm}$, as shown in Table 10 . Nozzle c makes a minimum depth of $40.13 \mathrm{~mm}$. The erosion pit of nozzle $\mathrm{c}$ is also featured with a minimum mouth diameter, as shown in Figure 13. The diameter of the mouth of the pit eroded by nozzle $\mathrm{a}$ is the second minimum and is slightly bigger than nozzle c. The conclusion of Section 3.3 tells that the diameter of the mouth is small if the shield effect is subtle. The difference of erosion volume and the depth between nozzles a and $\mathrm{c}$ is mainly caused by abrasive acceleration. Thus, the change of divergent angle causes the velocity of gas jet to decrease. This agrees well with the conclusion of Section 4.3. The main reason for the decrease of erosion volume and depth with 


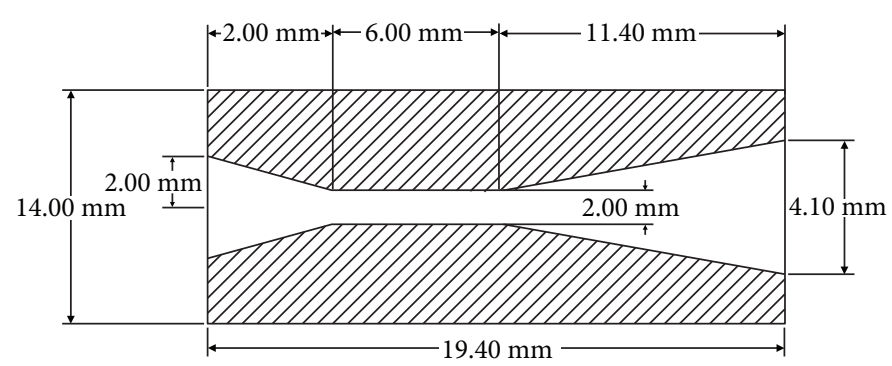

(a)

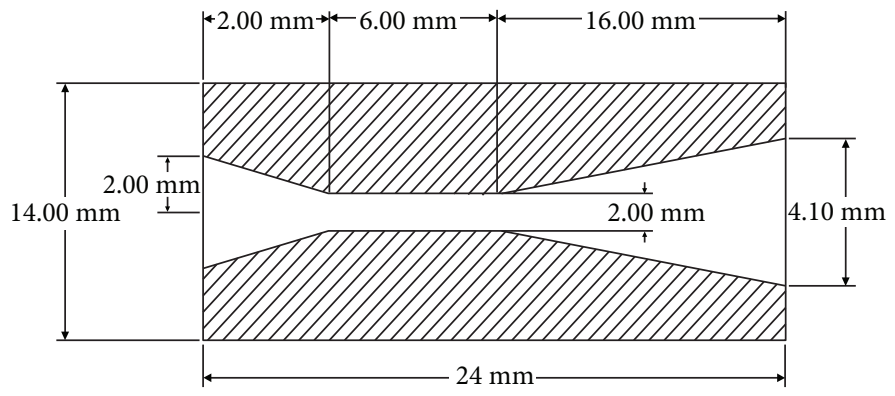

(c)

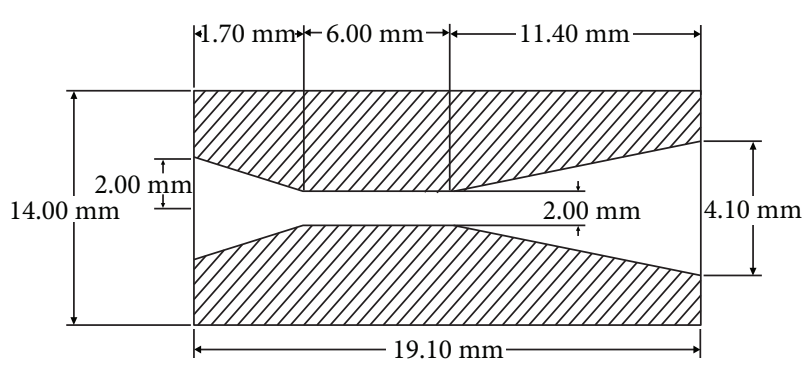

(b)

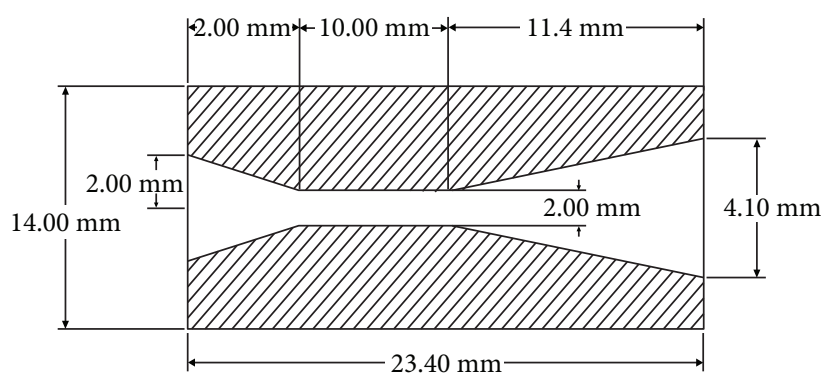

(d)

FIgURE 10: Nozzle used in the experiment of rock erosion.

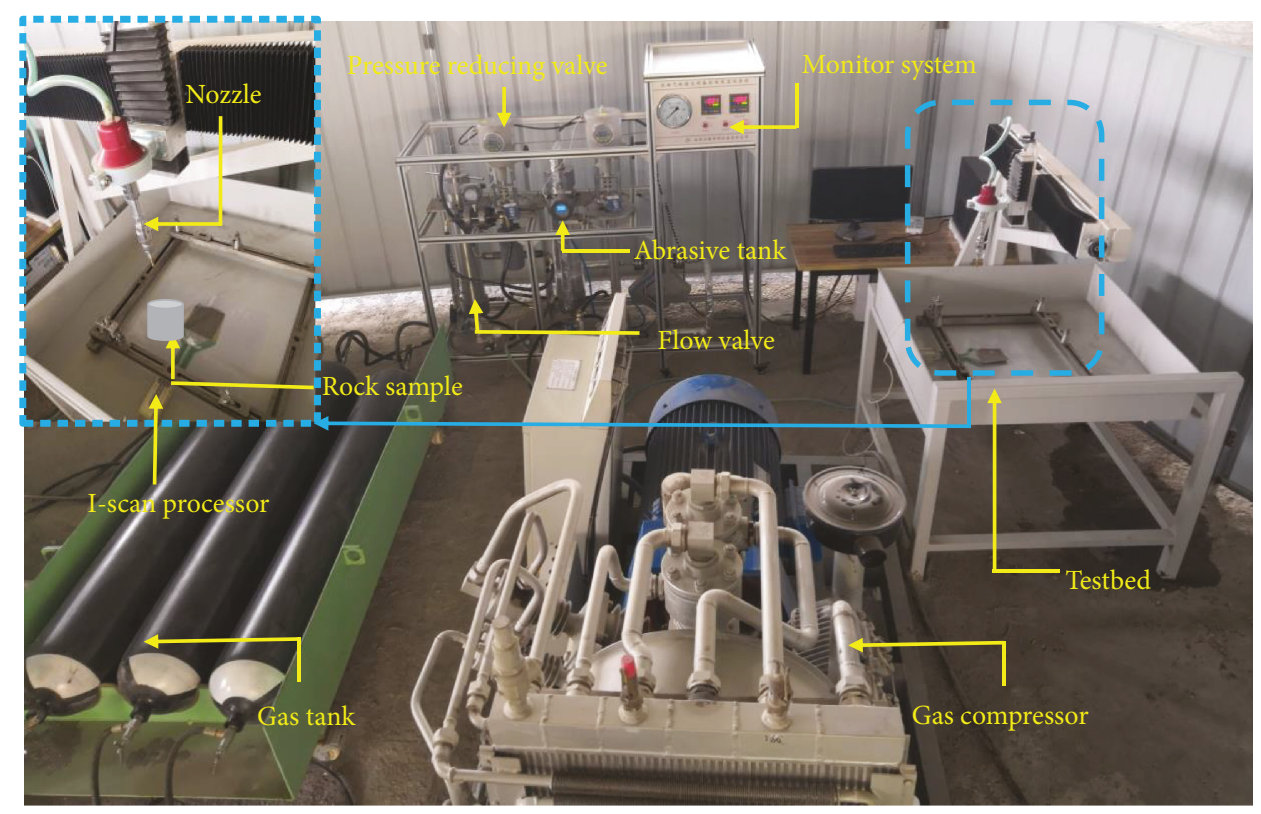

FIGURE 11: High-pressure abrasive air jet erosion system.

nozzles $b$ and $d$ is the shield effect. The changes of convergent angle and aspect ratio cause the velocity of the gas jet to increase and the shield effect to enhance, which is unfavorable to abrasive acceleration and rock erosion. These conclusions agree well with Sections 4.1 and 4.4. Thus, nozzle a is optimal, because it can induce a better flow field and less unobvious shield effects.

5.3. Further Experiment Validation. Is the nozzle still the optimal nozzle after changing the experimental conditions?
That is, whether nozzle a can still reach the maximum erosion rate when the type of abrasive and gas pressure is changed. To clarify the problem, different abrasives and gas pressure were used for erosion experiments.

(1) Abrasive Type. At present, the commonly used abrasives include quartz sand, garnet, brown corundum, and silicon carbide. Each nozzle uses four abrasives for rock erosion. By comparing the erosion parameters, this paper analyzes whether the variety of 


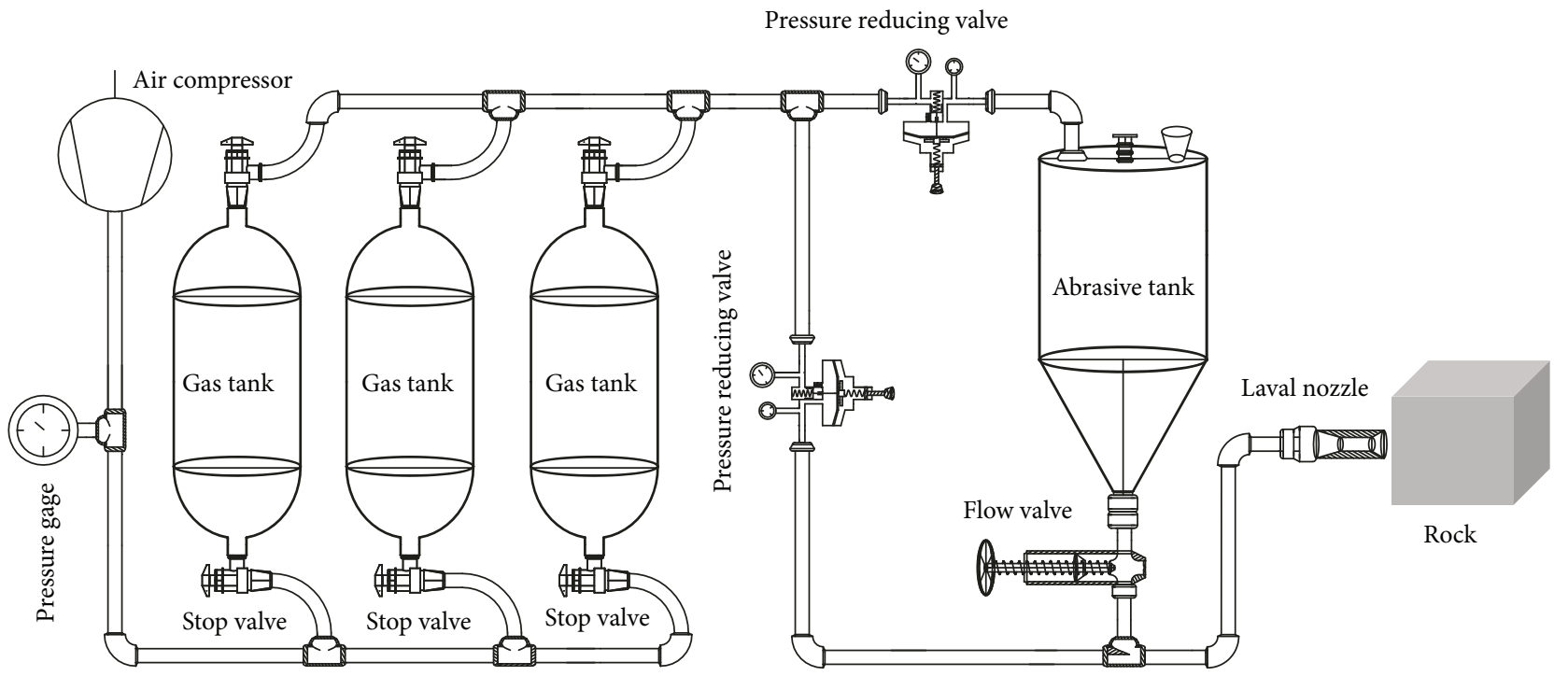

FIGURE 12: Connection schematic of high-pressure abrasive air jet erosion system.

TABLE 7: Limestone mechanical properties.

\begin{tabular}{lccc}
\hline $\begin{array}{l}\text { Sample } \\
\text { no. }\end{array}$ & $\begin{array}{c}\text { Uniaxial compressive } \\
\text { strength }(\mathrm{MPa})\end{array}$ & $\begin{array}{c}\text { Elastic modulus } \\
(\mathrm{E} / \mathrm{GPa})\end{array}$ & $\begin{array}{c}\text { Poisson's } \\
\text { ratio }(\mu)\end{array}$ \\
\hline 1 & 66.6 & 45.7 & 0.31 \\
2 & 66.4 & 45.2 & 0.32 \\
\hline
\end{tabular}

TABLE 8: Experiment procedure.

\begin{tabular}{lcc}
\hline Nozzle no. & $\begin{array}{c}\text { Erosion rock } \\
\text { sample no. }\end{array}$ & Experimental condition \\
\hline a & a-1, a-2, a-3 & Inlet pressure: $25 \mathrm{MPa}$ \\
b & b-1, b-2, b-3 & Erosion time: $10 \mathrm{~s}$ \\
c & c-1, c-2, c-3 & Abrasive: garnet with mesh 80 \\
d & d-1, d-2, d-3 & stand-off distance: $100 \mathrm{~mm}$ \\
\hline
\end{tabular}

TABLE 9: Erosion volume of different nozzle.

\begin{tabular}{lcccc}
\hline Nozzle & \multicolumn{3}{c}{ Erosion volume of rock } \\
samples $(\mathrm{mL})$ & Average $(\mathrm{mL})$ \\
\hline $\mathrm{a}$ & $1 \#$ & 2\# & 3\# & \\
$\mathrm{b}$ & 15.22 & 15.15 & 14.3 & 14.89 \\
$\mathrm{c}$ & 12.75 & 12.65 & 12.30 & 12.56 \\
$\mathrm{~d}$ & 9.30 & 9.25 & 9.60 & 9.38 \\
\hline
\end{tabular}

abrasives can influence the conclusion. The experimental pressure was $25 \mathrm{MPa}$, the target distance was $100 \mathrm{~mm}$, the erosion time was $10 \mathrm{~s}$, and the number of abrasives was 80 mesh. The experimental results are shown in Table 11. It can be seen that no matter which abrasive is used, nozzle a has the maximum erosion depth. Therefore, the optimal structure of nozzle a can be further determined.
TABLE 10: Erosion depth of the different nozzles.

\begin{tabular}{lcccc}
\hline Nozzle & \multicolumn{3}{c}{ Erosion depth of } & \\
& rock samples (mm) & Average (mm) \\
\hline a & 47.41 & 47.29 & 47.17 & 47.29 \\
b & 45.59 & 45.52 & 44.54 & 45.22 \\
c & 41.04 & 40.00 & 39.35 & 40.13 \\
d & 44.30 & 44.05 & 44.21 & 44.19 \\
\hline
\end{tabular}

(2) Gas Pressure. Gas pressure is one of the key factors to determine the erosion effect. Because the pressure of the air compressor applied in engineering is not very high, the gas pressure of the experiment is $10 \mathrm{MPa}$, $15 \mathrm{MPa}, 20 \mathrm{MPa}$, and $25 \mathrm{MPa}$. Four kinds of pressure were used to test the erosion of each nozzle. By comparing the erosion parameters, it is analyzed whether the change of gas pressure can affect the conclusion. The experimental abrasive was 80 mesh garnet, the target distance was $100 \mathrm{~mm}$, and the erosion time was $10 \mathrm{~s}$. The experimental results are shown in Table 12. It can be seen that gas pressure can affect the erosion depth, and the influence gradually decreases with the increase of gas pressure. However, under each experimental condition, nozzle a has the maximum erosion depth. Combined with the experimental results of different abrasive erosion, it can be concluded that nozzle a is the optimal structure.

\section{Conclusion}

Because nozzle structures are essential to erosion rates, it is necessary and vital to design an optimal nozzle to support a highly abrasive gas jet for rock breakage in coal-bed methane exploration. By combining aerodynamics and fixing the nozzle conditions, four types of nozzles were designed. The erosion rates of the nozzles were calculated using numerical 

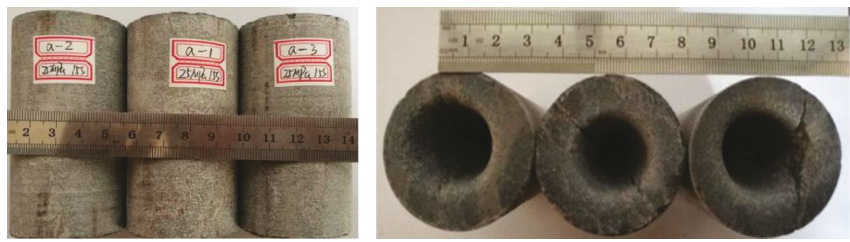

(a) Nozzle a
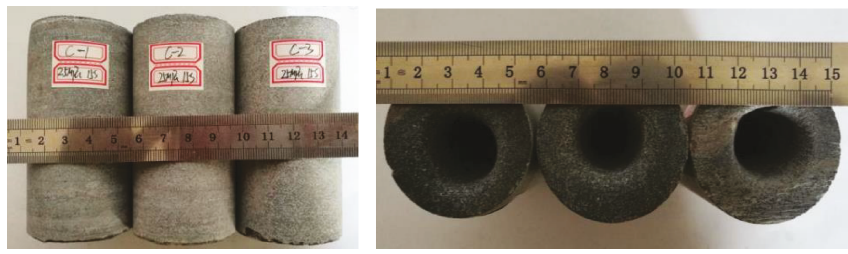

(c) Nozzle c
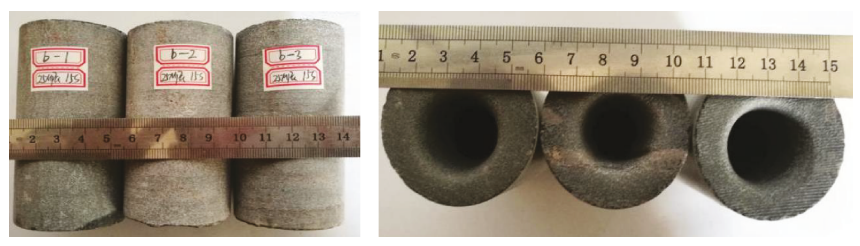

(b) Nozzle b
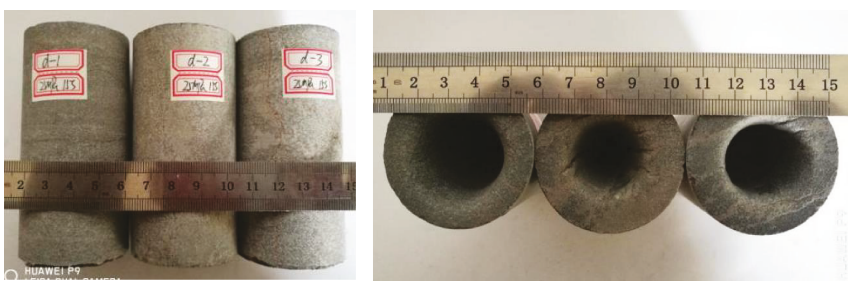

(d) Nozzle d

FIgURE 13: Erosion pit of rock.

TABLE 11: Erosion depth of the different nozzles when abrasive is different.

\begin{tabular}{lcccc}
\hline \multirow{2}{*}{ Abrasive type } & \multicolumn{4}{c}{ Erosion depth of rock samples (mm) } \\
& Nozzle a & Nozzle b & Nozzle c & Nozzle d \\
\hline Quartz sand & 40.21 & 38.83 & 33.62 & 37.81 \\
Garnet & 47.29 & 45.22 & 40.13 & 44.19 \\
Brown aluminium oxide & 52.49 & 50.64 & 45.18 & 47.25 \\
Silicon carbide & 53.39 & 50.89 & 46.16 & 48.42 \\
\hline
\end{tabular}

TABLE 12: Erosion depth of the different nozzles when gas pressure is different.

\begin{tabular}{lcccc}
\hline \multirow{2}{*}{ Gas pressure (MPa) } & \multicolumn{4}{c}{ Erosion depth of rock samples $(\mathrm{mm})$} \\
& Nozzle a & Nozzle b & Nozzle c & Nozzle d \\
\hline 10 & 30.57 & 26.49 & 22.84 & 25.28 \\
15 & 40.26 & 37.19 & 33.98 & 35.72 \\
20 & 46.58 & 43.87 & 40.20 & 42.90 \\
25 & 47.29 & 45.22 & 40.13 & 44.19 \\
\hline
\end{tabular}

simulation, showing that the Mach 3 nozzle was better with an inlet pressure of $25 \mathrm{MPa}$, and the best abrasive was garnet at 80 mesh. The optimal nozzle structure was featured with more extended expansion waves and more subtle shield effects.

To further optimize the nozzle structure, the erosion rates at various conditions were calculated using the single variable method. Thus, convergent angle, contraction ratio, divergent angle, and aspect ratio were changed at every turn to obtain the erosion rate. The optimal nozzle structure was obtained by comparing the erosion rate of different nozzle structures. Thus, the entrance diameter was $4 \mathrm{~mm}$, the convergent angle was $53^{\circ}$, the contraction ratio was 2 , the divergent angle was $10^{\circ}$, the aspect ratio was 3 , and the exit diameter was $4.1 \mathrm{~mm}$. The results of the rock erosion experiment show that it is in good agreement with the numerical simulation. The optimal nozzle can erode the maximum volume and depth.

\section{Data Availability}

The data of the paper refers to numerical simulation and experiment. Their calculation method and results are listed in the paper. That is, the data used to support the findings of this study are included within the article.

\section{Conflicts of Interest}

The authors declare that they have no conflicts of interest.

\section{Acknowledgments}

The authors disclosed receipt of the following financial support for the research, authorship, and/or publication of this article: this paper was jointly funded by the National Key Research and Development Program of China (2017YFC0804207), the National Science Foundation of China, (51704096, 51574112, and 51604092), Program for Innovative Research Team in University (IRT_16R22), the Science Research Funds for the Universities of Henan Province (J2018-4), and Scientific Research Foundation of State Key Laboratory Cultivation Base for Gas Geology and Gas Control (WS2017A02).

\section{References}

[1] J. Deng, L. Liu, and M. Ding, "Sand erosion performance of $\mathrm{SiC} /(\mathrm{W}, \mathrm{Ti}) \mathrm{C}$ gradient ceramic nozzles by abrasive air-jets," Materials \& Design, vol. 28, no. 7, pp. 2099-2105, 2007.

[2] C. H. Hamilton and D. F. Hasson, Advanced Processing Methods for Titanium: Casting, Forming, Machining, Welding: Proceedings of a Symposium, Metallurgical Society of AIME, 1982.

[3] J. M. Fan, C. Y. Wang, and J. Wang, "Modelling the erosion rate in micro abrasive air jet machining of glasses," Wear, vol. 266, no. 9-10, pp. 968-974, 2009.

[4] Z. Wen, Y. Liu, X. Liu, and B. Liang, "Experimental research into the effects of abrasive characteristics on abrasive gas jet coal-breaking performance," International Journal of Heat and Technology, vol. 35, no. 1, pp. 32-36, 2017. 
[5] Y. Liu, B. Liang, and X. Liu, "Experimental and numerical optimization of coal breakage performance parameters through abrasive gas jet," International Journal of Heat and Technology, vol. 35, no. 4, pp. 747-754, 2017.

[6] Y. Liu, T. Zhang, and X. Liu, "Analysis of the stress wave effect during coal breakage by a high-pressure abrasive air jet," Advances in Mechanical Engineering, vol. 10, no. 6, 2018.

[7] Y. Liu, J. Wei, and T. Ren, "Analysis of the stress wave effect during rock breakage by pulsating jets," Rock Mechanics and Rock Engineering, vol. 49, no. 2, pp. 503-514, 2016.

[8] Y. Liu, J. Wei, T. Ren, and Z. Lu, "Experimental study of flow field structure of interrupted pulsed water jet and breakage of hard rock," International Journal of Rock Mechanics and Mining Sciences, vol. 78, pp. 253-261, 2015.

[9] Y. Liu, B. Xia, and X. Liu, "A novel method of orienting hydraulic fractures in coal mines and its mechanism of intensified conduction," Journal of Natural Gas Science and Engineering, vol. 27, pp. 190-199, 2015.

[10] M. Huang, Y. Kang, X. Wang et al., "Experimental investigation on the impingement characteristics of a self-excited oscillation pulsed supercritical carbon dioxide jet," Experimental Thermal and Fluid Science, vol. 94, pp. 304-315, 2018.

[11] S. Bühler, T. Luginsland, D. Obrist, and L. Kleiser, "Parallel simulation of a compressible jet including nozzle modelling," PAMM, vol. 10, no. 1, pp. 443-444, 2010.

[12] D. H. Tan, P. K. Herman, A. Janakiraman, F. S. Bates, S. Kumar, and C. W. Macosko, "Influence of Laval nozzles on the air flow field in melt blowing apparatus," Chemical Engineering Science, vol. 80, pp. 342-348, 2012.

[13] Z. D. Li, G. Q. Zhang, Z. Li, Y. Zhang, and W. Y. Xu, "Simulation of gas flow field in Laval nozzle and straight nozzle for powder metallurgy and spray forming," Journal of Iron and Steel Research, International, vol. 15, no. 6, pp. 44-47, 2008.

[14] A. P. Alkhimov, V. F. Kosarev, and S. V. Klinkov, "The features of cold spray nozzle design," Journal of Thermal Spray Technology, vol. 10, no. 2, pp. 375-381, 2001.

[15] M. Huang, Y. Kang, X. Long et al., "Effects of a nano-silica additive on the rock erosion characteristics of a $\mathrm{SC}-\mathrm{CO}_{2}$ jet under various operating conditions," Applied Sciences, vol. 7, no. 2, p. 153, 2017.

[16] A. E. Green, "Compressible fluid jets," Archive for Rational Mechanics and Analysis, vol. 59, no. 3, pp. 189-205, 1975.

[17] S. Junlong, L. Changxia, T. Jin, and F. Baofu, "Erosion behavior of $\mathrm{B}_{4} \mathrm{C}$ based ceramic nozzles by abrasive air-jet," Ceramics International, vol. 38, no. 8, pp. 6599-6605, 2012.

[18] F. De Gregorio, "Free compressible jet investigation," Experiments in Fluids, vol. 55, no. 3, p. 1693, 2014.

[19] T. Frosell, M. Fripp, and E. Gutmark, "Investigation of slurry concentration effects on solid particle erosion rate for an impinging jet," Wear, vol. 342-343, pp. 33-43, 2015.

[20] Q. Li, J. Li, G. Q. He, and P. J. Liu, "Erosion of carbon/carbon composites using a low-velocity, high-particle-concentration two-phase jet in a solid rocket motor," Carbon, vol. 67, pp. 140-145, 2014.

[21] T. Deng, A. R. Chaudhry, M. Patel, I. Hutchings, and M. S. A. Bradley, "Effect of particle concentration on erosion rate of mild steel bends in a pneumatic conveyor," Wear, vol. 258, no. 1-4, pp. 480-487, 2005.

[22] M. M. Stack and S. M. Abdelrahman, "A CFD model of particle concentration effects on erosion-corrosion of Fe in aqueous conditions," Wear, vol. 273, no. 1, pp. 38-42, 2011.
[23] H. X. Hu and Y. G. Zheng, "The effect of sand particle concentrations on the vibratory cavitation erosion," Wear, vol. 384-385, pp. 95-105, 2017.

[24] R. D. Aponte, L. A. Teran, J. A. Ladino, F. Larrahondo, J. J. Coronado, and S. A. Rodriguez, "Computational study of the particle size effect on a jet erosion wear device," Wear, vol. 374-375, pp. 97-103, 2017.

[25] C. Trevisiol, A. Jourani, and S. Bouvier, "Effect of hardness, microstructure, normal load and abrasive size on friction and on wear behaviour of 35NCD16 steel," Wear, vol. 388-389, pp. 101-111, 2017.

[26] Z. Amiri and S. Movahedirad, "Bubble-induced particle mixing in a 2-D gas-solid fluidized bed with different bed aspect ratios: a CFD-DPM study," Powder Technology, vol. 320, pp. 637-645, 2017.

[27] M. Dan, "Numerical simulation about the effect rules of particles concentration on erosion of the centrifugal fan," Advanced Materials Research, vol. 594-597, pp. 2162-2166, 2012.

[28] W. Peng and X. Cao, "Numerical simulation of solid particle erosion in pipe bends for liquid-solid flow," Powder Technology, vol. 294, pp. 266-279, 2016.

[29] Z. Zhu, T. Feng, Z. Yuan, D. Xie, and W. Chen, "Solid-gas coupling model for coal-rock mass deformation and pressure relief gas flow in protection layer mining," Advances in Civil Engineering, vol. 2018, 6 pages, 2018.

[30] N. Koutsourakis, J. G. Bartzis, and N. C. Markatos, "Evaluation of Reynolds stress, $k-\varepsilon$ and RNG $k-\varepsilon$ turbulence models in street canyon flows using various experimental datasets," Environmental Fluid Mechanics, vol. 12, no. 4, pp. 379-403, 2012.

[31] G. Hu, P. Zhang, G. Wang et al., "Performance study of erosion resistance on throttle valve of managed pressure drilling," Journal of Petroleum Science and Engineering, vol. 156, pp. 29-40, 2017.

[32] H. Arabnejad, A. Mansouri, S. A. Shirazi, and B. S. McLaury, "Abrasion erosion modeling in particulate flow," Wear, vol. 376-377, pp. 1194-1199, 2017.

[33] X. Chen, B. S. McLaury, and S. A. Shirazi, "Application and experimental validation of a computational fluid dynamics (CFD)-based erosion prediction model in elbows and plugged tees," Computers \& Fluids, vol. 33, no. 10, pp. 1251-1272, 2004.

[34] S. A. Morsi and A. J. Alexander, "An investigation of particle trajectories in two-phase flow systems," Journal of Fluid Mechanics, vol. 55, no. 2, pp. 193-208, 1972. 

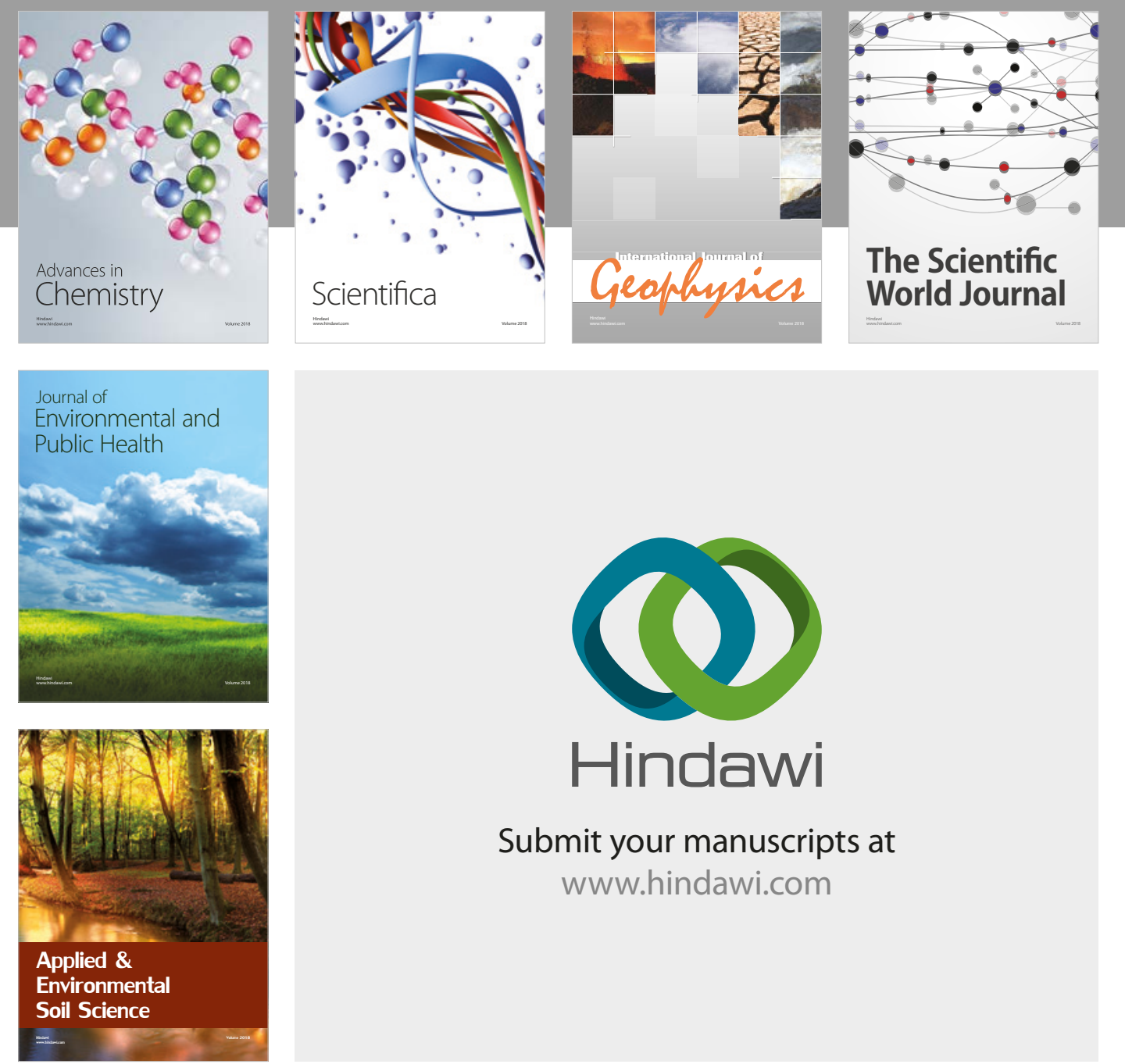

The Scientific

\section{World Journal}
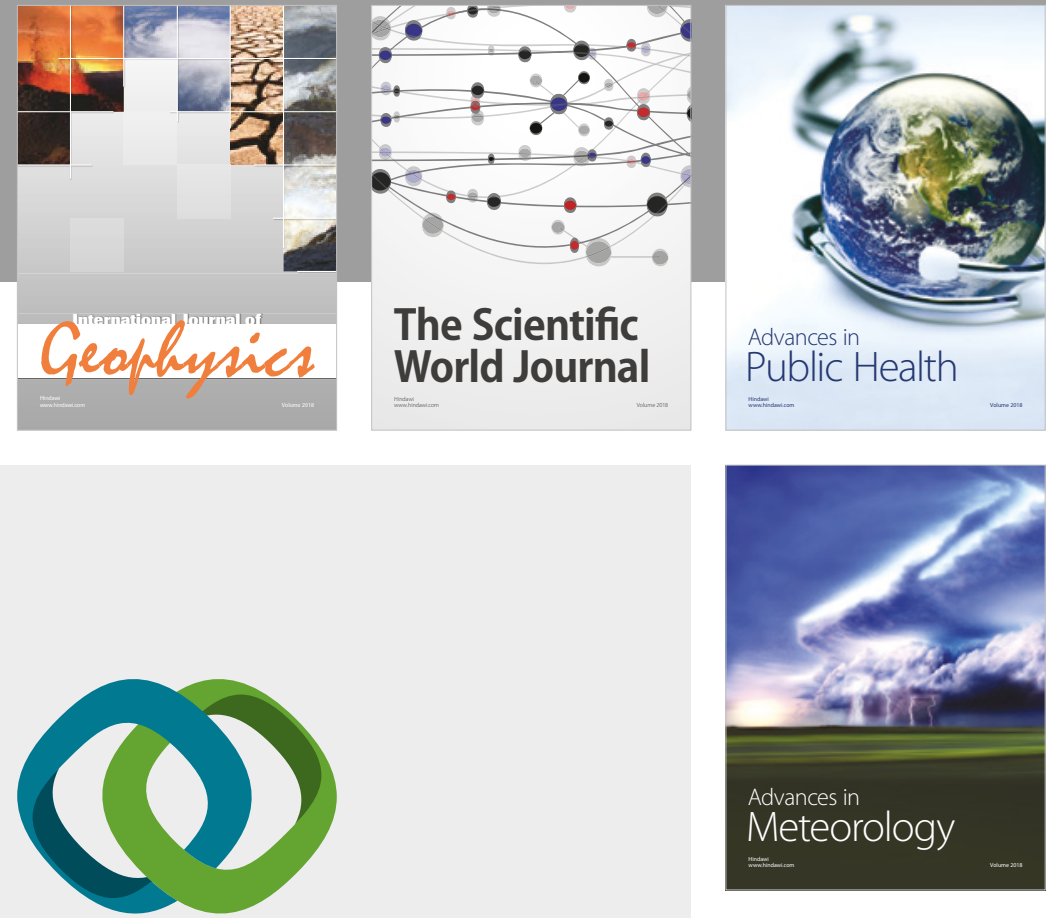

Advan

Public Health

\section{Hindawi}

Submit your manuscripts at

www.hindawi.com
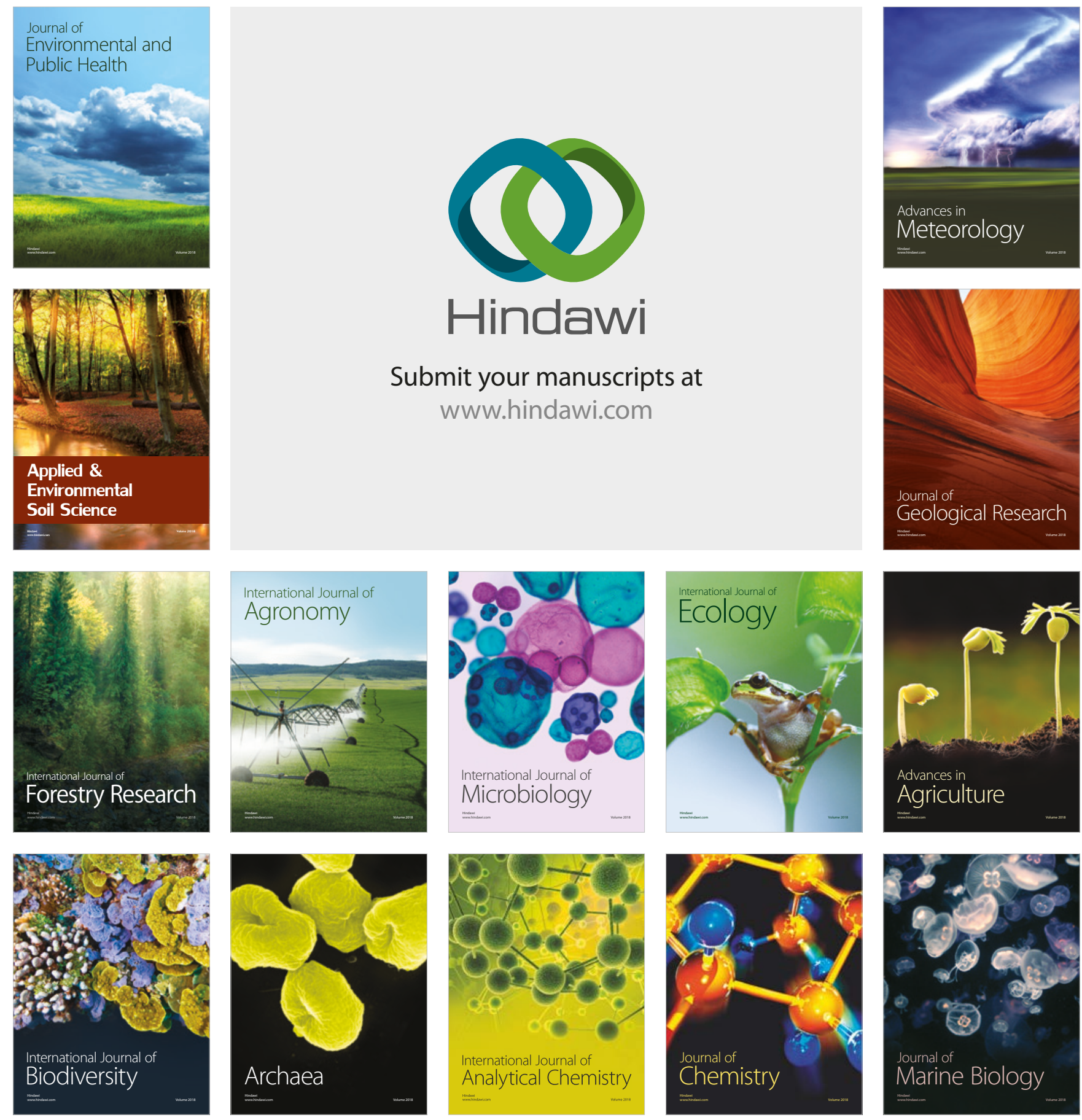